\title{
Granulysin, a novel marker for extranodal NK/T cell lymphoma, nasal type
}

\author{
Giuseppe Lo Bello ${ }^{1}$. Ayse U. Akarca ${ }^{2}$ - Maria Raffaella Ambrosio ${ }^{1}$. Claudio Agostinelli ${ }^{3} \cdot$ Hernan Molina-Kirsch $^{4}$. \\ Alan Ramsay ${ }^{5}$. Manuel Rodriguez-Justo ${ }^{5}$ Matt Pugh ${ }^{6}$. Shuchun Zhao ${ }^{7}$. Monique DeLisser ${ }^{7}$. Elena Sabattini ${ }^{3}$. \\ Stefan Dojcinov ${ }^{6} \cdot$ Stefano A. Pileri $^{8,9} \cdot$ Yasodha Natkunam $^{7} \cdot$ Lorenzo Leoncini $^{1} \cdot$ Teresa Marafioti $^{2}$
}

Received: 17 April 2018 /Revised: 3 August 2018 / Accepted: 7 August 2018 / Published online: 27 August 2018

(C) The Author(s) 2018

\begin{abstract}
Granulysin is a cytolytic protein expressed in cytotoxic T and natural killer (NK) cells. Abnormal serum levels of granulysin in lymphomas with NK and cytotoxic phenotype have been shown to correlate with tumour progression. In this study, we investigated the expression pattern of granulysin in routine sections of normal and reactive lymphoid tissues as well as in a large series of lymphomas. In normal tissues, granulysin labelled a small population of cells that double immunostaining revealed to belong to the pool of cytotoxic T/NK cells. Among lymphoid neoplasms, the highest expression of granulysin (71\%) was found in extranodal NK/T cell lymphomas of nasal type (ENKTL). To note is that $29 \%$ of ENKTLs, which were negative for one or more of classical cytotoxic markers strongly expressed granulysin. Furthermore, expression of granulysin was observed in rare cases of T cell lymphomas with a cytotoxic phenotype (i.e. ALK-negative anaplastic large cell lymphoma (26\%), enteropathy-associated T cell lymphoma (12\%) and peripheral T cell lymphoma, NOS (4\%)). None of the investigated non-Hodgkin B cell lymphomas, Hodgkin lymphoma and plasma cell myeloma were granulysin positive. The results suggest granulysin as a novel marker for a subset of cytotoxic NK cell derived malignancies and its usefulness is highlighted in those ENKTLs that lack expression of other cytotoxic markers but retain granulysin expression.
\end{abstract}

Keywords T cell lymphoma $\cdot$ Immunohistochemistry $\cdot$ Granulysin $\cdot$ NK-T cells $\cdot$ Phenotype

\section{Introduction}

Granulysin is a sposin-like lipid-binding protein that was originally described in 1998 as a human antimicrobial peptide with a broad activity against intracellular pathogens [1]. The protein was initially identified as a cytolytic and proinflammatory molecule expressed by natural killer (NK) cells and activated cytotoxic T lymphocytes (CTLs) [2, 3]. It is

Ayse U. Akarca and Maria Raffaella Ambrosio contributed equally to this work.

Teresa Marafioti

t.marafioti@ucl.ac.uk

1 Department of Medical Biotechnologies, Section of Pathology, University of Siena, 53100 Siena, Italy

2 Department of Histopathology, University College London, University College Hospital, Rockefeller Building, UCL Site, 21 University Street, London WC1E 6JJ, UK

3 Haematopathology Unit, Department of Experimental Diagnostic and Specialty Medicine, S. Orsola-Malpighi Hospital, University of Bologna, 40138 Bologna, Italy

4 Department of Pathology, San Juan General Hospital, 10303 Guatemala City, Guatemala
5 Department of Cellular Pathology, University College Hospital London, London WC1E 6JJ, UK

6 Department of Pathology, University Hospital of Wales, Cardiff CF14 4XW, UK

7 Department of Pathology, Stanford University School of Medicine, Stanford, CA 94305-5324, USA

8 University of Bologna, University School of Medicine, 40138 Bologna, Italy

9 Italy and Unit of Haematopathology, European Institute of Oncology, IEO, Milan, Italy 
localised within granules and associated with other poreforming proteins like perforin and granzyme [1, 4].

Several studies have shown the clinical relevance of granulysin in a number of physiologic conditions including reproductive biology, innate immunity, dendritic cell chemotaxis and activation as well as in infectious diseases and in cancers [5-7]. It has been shown that serum levels of granulysin in patients with mature NK neoplasms were abnormal and heterogeneously expressed [8]. The findings led to suggest granulysin as a potential diagnostic and prognostic marker for these lymphoma types [8].

Mature NK/T cell lymphomas are distinct clinicopathological entities and include extranodal NK/T cell lymphoma, nasal type (ENKTL), aggressive NK-cell leukaemia (ANKL) and chronic lymphoproliferative disorders of NK cells (CLPD-NK) [9]. ENKTL predominantly occurs in Asian and Central/South American populations, shows frequent involvement of extra-nodal sites [9-12] though nodal localizations are described and it is associated with Epstein-Barr virus (EBV) infection [10]. The neoplastic cells show variable expression of NK and cytotoxic $\mathrm{T}$ cell markers and molecular studies demonstrated $\mathrm{T}$ cell receptor (TCR) gene rearrangements only in a minority of cases [9].

The diagnosis of ENKTL is often challenging due to the variable morphologic and immunophenotypic features [13-15] overlapping sometimes to those of subsets of $\mathrm{T}$ cell lymphomas with cytotoxic phenotype and pathologists need additional and robust markers to achieve precision diagnosis. Identification of a novel marker that can help in this diagnostic setting is of interest.

In the present investigation, we carried out an immunohistochemical analysis of granulysin, in normal and neoplastic lymphoid tissues, with the aim to assess its potential utility to refine the diagnosis of NK/T cell lymphoma subtypes.

\section{Materials and methods}

Patients and tissue samples Formalin-fixed paraffinembedded (FFPE) tissue blocks were retrieved from the files of the Departments of Histopathology, University College Hospital, London, UK; Pathology, Stanford University School of Medicine, CA, USA; Pathology, University Hospital of Wales, Cardiff, UK; and from the Units of Pathology, University Hospital Siena and of Haematopathology, S. Orsola Malpighi Hospital, University of Bologna, Italy. In addition, sections of tissue microarrays (TMAs) constructed from FFPE tissue samples of T cell lymphoma subtypes, as reported previously [16], were also included. The tissue-microarrays were generated upon selection of representative, tumour-rich areas by two expert haematopathologists (YN and HM-K) and were retrieved from the files of the Departments of Pathology, Stanford
University School of Medicine, Stanford, USA, and San Juan General Hospital Guatemala City, Guatemala.

The samples included in this investigation consisted of normal lymphoid tissues comprising thymus $(n=1)$, tonsils $(n=4)$, lymph node $(n=1)$, spleen $(n=1)$, two lymph nodes showing reactive changes specific of EBVassociated lymphadenitis (i.e. infectious mononucleosis), five lymph nodes with the diagnosis of chronic active EBV infection (CAEBV), and a large series of nonHodgkin and Hodgkin lymphomas (Table 1).

Primary diagnosis was performed at each Institution by expert haematopathologists according to the criteria of the updated World Health Organization classification of Tumors of Haematopoietic and Lymphoid Tissues [9].

IHC and antibodies Immunohistochemistry (IHC) was carried out on a Bond-III Autostainer (Leica Microsystems, Newcastle upon Tyne, UK) as previously described [17]. The following mouse monoclonal antibodies raised against fixation-resistant epitopes were applied: anti-granulysin (clone F-9, dilution 1:300, Santa Cruz, Santa Cruz Biotechnology, Inc., TX, USA), anti-CD3 (clone LN10, dilution 1:100, Leica Microsystems Ltd., Newcastle-upon-Tyne, UK), anti-CD5 (clone 4C7; dilution 1:100, Leica

Table 1 Expression of granulysin in haematological neoplasms

\begin{tabular}{|c|c|c|}
\hline \multicolumn{2}{|c|}{ Lymphoma/leukaemia entity } & \multirow{2}{*}{$\frac{n / N(\%)}{0 / 10}$} \\
\hline B cell lymphoma & Chronic lymphocytic leukaemia & \\
\hline & Mantle cell lymphoma & $0 / 10$ \\
\hline & Follicular lymphoma & $0 / 10$ \\
\hline & Diffuse large B cell lymphoma & $0 / 10$ \\
\hline & T-cell/histiocyte-rich large B cell lymphoma & $0 / 7$ \\
\hline & Burkitt lymphoma & $0 / 9$ \\
\hline & Hairy cell leukaemia & $0 / 7$ \\
\hline & $\begin{array}{l}\text { Chronic active EBV infection } \\
\text { (CAEBV), B cell type }\end{array}$ & $0 / 1$ \\
\hline \multirow[t]{11}{*}{$\begin{array}{l}\text { T/NK cell } \\
\text { lymphoma }\end{array}$} & $\begin{array}{l}\text { Extranodal NK/T cell lymphoma, } \\
\text { nasal type }\end{array}$ & $\begin{array}{l}61 / 86 \\
\quad(71 \%)\end{array}$ \\
\hline & $\begin{array}{l}\text { ALK-negative anaplastic large cell lymphoma } \\
\text { (ALK-ALCL) }\end{array}$ & $\begin{array}{l}4 / 15 \\
\quad(26 \%)\end{array}$ \\
\hline & $\begin{array}{l}\text { Enteropathy-associated T-cell lymphoma } \\
\text { (EATL) }\end{array}$ & $\begin{array}{l}1 / 8 \\
(12 \%)\end{array}$ \\
\hline & $\begin{array}{l}\text { Peripheral T-cell lymphoma, NOS } \\
\text { (PTCL, NOS) }\end{array}$ & $\begin{array}{l}2 / 50 \\
(4 \%)\end{array}$ \\
\hline & T-cell large granular lymphocytic leukaemia & $0 / 8$ \\
\hline & Angioimmunoblastic T-cell lymphoma & $0 / 24$ \\
\hline & $\begin{array}{l}\text { ALK-positive anaplastic large cell lymphoma } \\
(\text { ALK+ALCL) }\end{array}$ & $0 / 5$ \\
\hline & Hepatosplenic T-cell lymphoma & $0 / 8$ \\
\hline & T-lymphoblastic leukaemia (T-ALL) & $0 / 6$ \\
\hline & Adult T cell leukaemia/lymphoma (ATLL) & $0 / 6$ \\
\hline & CAEBV, T cell type & $0 / 4$ \\
\hline \multirow{2}{*}{$\begin{array}{l}\text { Hodgkin } \\
\text { lymphoma }\end{array}$} & Classical & $0 / 20$ \\
\hline & Lymphocyte predominant & $0 / 29$ \\
\hline $\begin{array}{l}\text { Plasma cells } \\
\text { neoplasms }\end{array}$ & Myeloma & $0 / 10$ \\
\hline
\end{tabular}

$n$ number of cases positive for granulysin, $N$ total number of cases, $\%$ percentage of positive cases, NOS not otherwise specified 
Microsystems Ltd., Newcastle-upon-Tyne, UK), anti-CD2 (clone 11F11, dilution RTU, Leica Microsystems Ltd., Newcastle-upon-Tyne, UK), anti-CD7 (clone LP15, dilution RTU, Leica Microsystems Ltd., Newcastle-upon-Tyne, UK), anti-CD4 (clone 4B12, dilution RTU, Leica Microsystems Ltd., Newcastle-upon-Tyne, UK), anti-CD8 (clone 4B11, dilution RTU, Leica Microsystems Ltd., Newcastle-upon-Tyne, UK), anti-CD30 (clone JCM182, dilution RTU, Leica Microsystems Ltd., Newcastle-upon-Tyne, UK), anti-CD43 (clone MT1, dilution RTU, Leica Microsystems Ltd., Newcastle-upon-Tyne, UK), anti-CD56 (clone CD564, dilution RTU, Leica Microsystems Ltd., Newcastle-upon-Tyne, UK), anti-granzyme B (clone 11F1, dilution RTU, Leica Microsystems Ltd., Newcastle-upon-Tyne, UK), anti-TIA-1 (clone 2G9A10F5, dilution 1:150, Beckman Coulter Ltd., High Wycombe, UK), anti-perforin (clone 5B10, dilution 1:30, Leica Microsystems Ltd., Newcastle-upon-Tyne, UK).

To investigate the expression pattern of granulysin in lymphoid cell subsets, sections of reactive tonsil and lymph node as well as lymph node of patients with infectious mononucleosis were analysed to double immunostaining using a protocol described elsewhere [18]. The antibodies panels consisted of granulysin in combination with one of the following molecules: CD4, CD8, CD56 and granzyme B.

In ENKTL cases staining for CD56, granzyme B, TIA1 and perforin was assessed as percentage of positive tumour cells over the total number of cells.

The review and scoring of the staining was performed by expert haematopathologists (GLB, MRA, LL, YN and TM) who were blinded to each other and to the clinical history and original diagnosis.

The score to assess the percentage of positive cells over the number of all cells was set as it follows: 1 (10-25\% positive cells), 2 (25-75\% positive cells) and 3 (>75\% positive cells) [19].

Five different fields (at least 100 cells/field) were evaluated at $\times 200$ magnification. Cases with discrepant scoring were reviewed jointly by two out of the four haematopathologists to reach a final consensus.

Detection of EBV In situ hybridization for detection of the EBV-encoded small RNAs (EBER) was performed using the INFORM EBER Probe (Ventana/ROCHE, Tucson, AZ, US). The technique was carried out in the
Fig. 1 Expression of granulysin in normal lymphoid tissues. Tonsil (a, b), lymph node $(\mathbf{c}, \mathbf{d})$, spleen $(\mathbf{e}, \mathbf{f})[\mathbf{a}, \mathbf{c}, \mathbf{e}$ original magnification (O.M.): $\times 10 ; \mathbf{b}, \mathbf{d}$, f O.M. × 20]
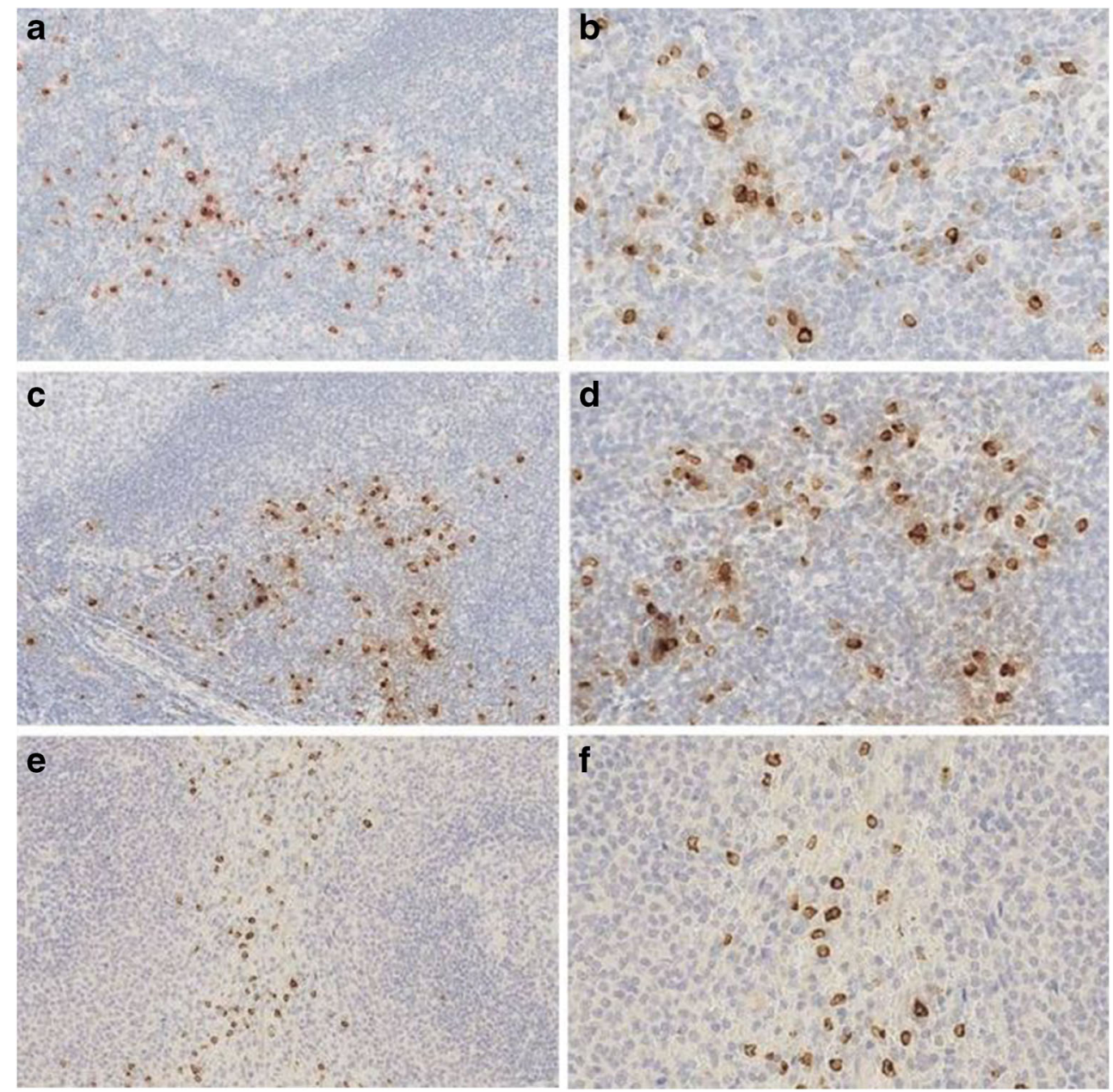
BenchMark Ultra (Ventana/ROCHE) platform according to the manufacturer's instructions, as previously described [20].

Statistical analysis Chi-square test $(99 \% \mathrm{CI})$ and $\mathrm{GraphPad}$ Software (La Jolla, CA, USA) were used to calculate the $p$ value in the statistical analysis.

\section{Results}

\section{Granulysin expression in non-neoplastic lymphoid tissues}

Granulysin showed a membranous and intracellular (dot-like) staining restricted to a small population of cells in the interfollicular areas of reactive tonsils and lymph nodes (Fig. 1). In the red pulp of the spleen and in the medulla of the thymus, scattered granulysin-positive cells were seen (Fig. 1). Double immunostaining carried out in tissue sections of reactive tonsil and lymph node demonstrated that the granulysin-positive cells were mostly CD4 negative and few co-expressed CD8. The majority of granulysin-positive cells co-expressed CD56 (Fig. 2).

B cells, plasma cells, macrophages, epithelioid histiocytes and dendritic cells were granulysin negative.

\section{Granulysin expression in CAEBV}

Five lymph nodes with the diagnosis of CAEBV were included in this study. All cases showed EBV infection by EBER-
ISH and strongly expressed one or more of the following markers: CD2, CD3, CD8, TIA-1, granzyme B and perforin. Four out of five cases were T cell type CAEBV (also confirmed by PCR detection of a monoclonal TCR rearrangement), and the remaining case was of B cell type.

Only scattered lymphocytes, expressing one or more cytotoxic markers, were granulysin positive.

\section{Granulysin expression in haematological malignancies}

Table 1 summarises the results of granulysin in a series of haematological malignancies.

Granulysin was found to be mainly restricted to some NK/T cell lymphoma subtypes, and the highest expression was observed in ENKTLs $(61 / 86 ; 71 \%)$. All the investigated ENKTL cases were EBER-positive and strongly expressed one or more of the cytotoxic markers (i.e. CD56, granzyme B, TIA-1 and perforin) and/or CD2, CD3, CD7 and CD43 (Table 2).

The intensity of granulysin in the 61 positive ENKTLs was strong and comparable to that of the other cytotoxic markers, and in each case, more than $75 \%$ of tumour cells were positive (score 3, Fig. 3). To note is that 26 out of the 61 granulysin-positive cases showed a statistically significant lower level of expression of the other cytotoxic markers $(p<0.01)$ whereas granulysin was homogeneous and strong in all instances. Table 3 summarises the clinicopathological data of the 26 cases with strong granulysin expression and lack of one or all others cytotoxic markers (Figs. 4 and 5).

Fig. 2 Double immunostaining of granulysin and T/NK cell markers in reactive tonsils. CD4-positive cells are granulysin negative (a); a few CD8-positive cells coexpressed granulysin (b). The majority of CD56-positive cells were granulysin positive (c). In all images, granulysin is in blue with the exception in $\mathbf{b}$ which is in brown. No counterstaining is performed. [O.M.: a-c $\times 20$ ]

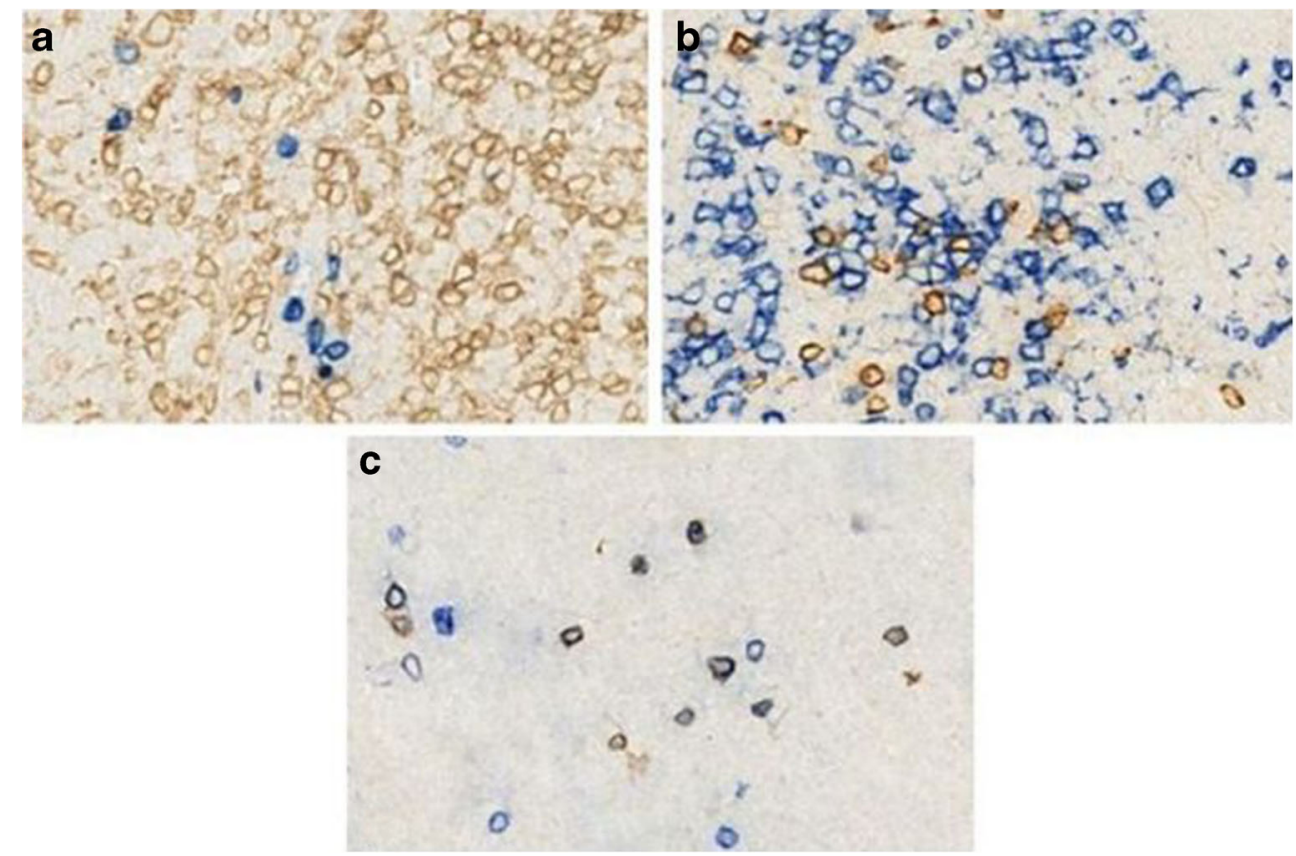


Table 2 Immunohistochemical and in situ hybridization results in nasal-type extranodal NK/T cell lymphomas

\begin{tabular}{lc}
\hline Marker & Positivity $(n / N)$ \\
\hline Granulysin & $71 \%(61 / 86)$ \\
CD56 & $98,8 \%(85 / 86)$ \\
Granzyme B & $77 \%(66 / 86)$ \\
TIA-1 & $68 \%(59 / 86)$ \\
Perforin & $40 \%(34 / 86)$ \\
EBER & $100 \%(86 / 86)$ \\
CD2 & $86 \%(49 / 57)$ \\
CD3 (cytoplasmic) & $76 \%(65 / 86)$ \\
CD7 & $75 \%(6 / 8)$ \\
CD43 & $100 \%(42 / 42)$ \\
CD5 & $3,6 \%(2 / 56)$ \\
CD30 & $16 \%(7 / 43)$ \\
\hline
\end{tabular}

$n$ number of cases positive for granulysin, $N$ total number of cases, $\%$ percentage of positive cases
In the remaining 25 ENKTL cases (29\%), the neoplastic cells were consistently granulysin negative; the clinicopathological data of these cases are detailed in Table 4. We may conclude that the majority of granulysin-negative ENKTCL cases lack expression of perforin. Moreover, all granulysin-negative cases arose from upper digestive tract (nasal cavity, nasopharynx, paranasal sinus and palate) while many strongly granulysin-positive cases are from skin, testis and gastrointestinal tract (stomach, small intestine and large bowel).

Furthermore, weak granulysin positivity (score 1) was seen in 4 out of 15 (26\%) ALK-negative anaplastic large cell lymphomas (ALK-ALCL), 1 out of 8 (12\%) enteropathyassociated $\mathrm{T}$ cell lymphomas (EATL, all cases are type I)
Fig. 3 Granulysin ENKTL lymphomas with different organs involvement. Nasal cavity (a, b), rete testis $(\mathbf{c}, \mathbf{d})$, skin $(\mathbf{e}, \mathbf{f})[\mathbf{a}, \mathbf{c}$ O.M. × 10; e O.M. × 2.5; b, d, f O.M. $\times 20]$
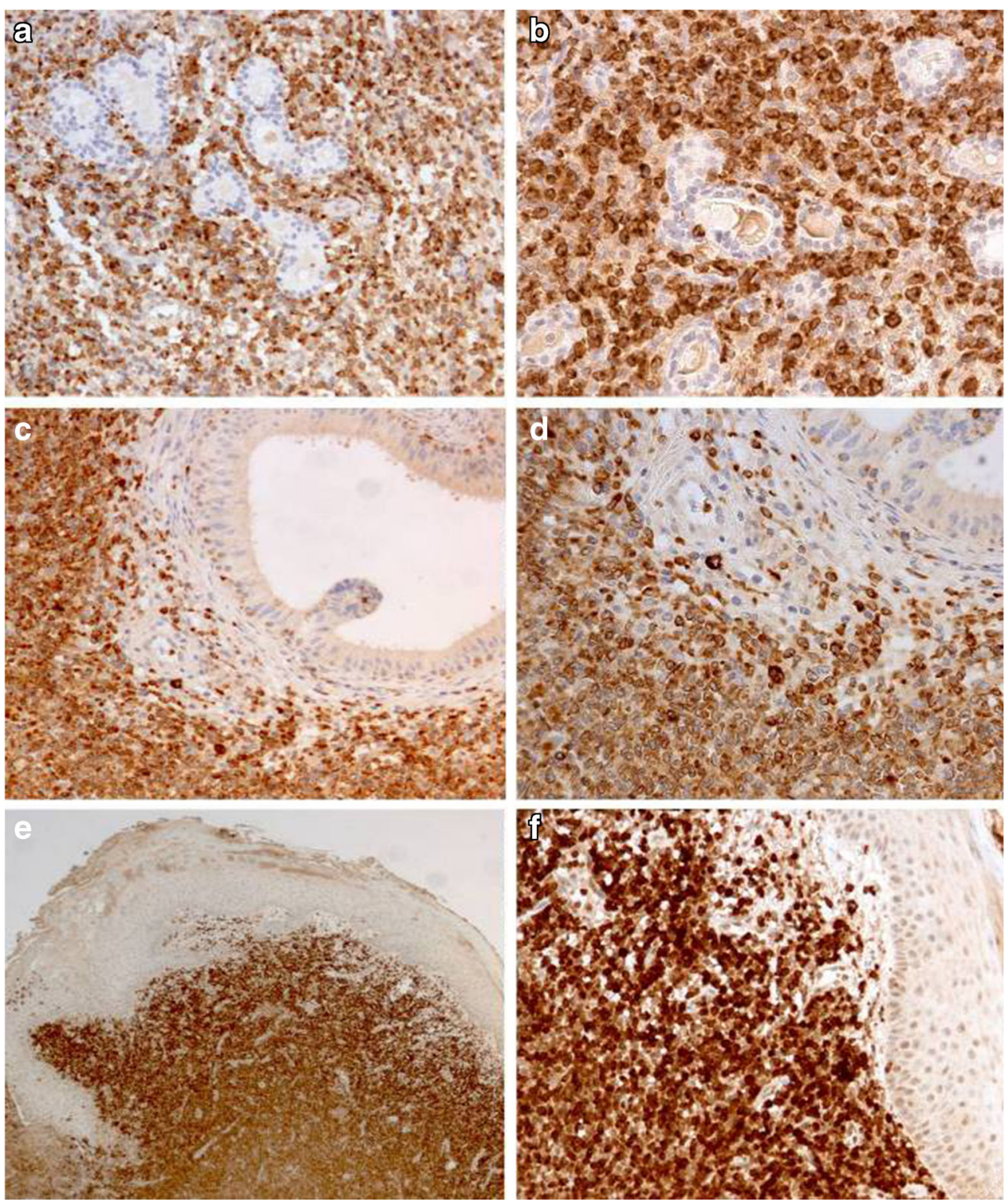
Table 3 Immunohistochemical features of granulysin-positive ENKTL cases with lower level of expression of the other cytotoxic markers

\begin{tabular}{|c|c|c|c|c|c|c|c|c|c|c|}
\hline Case & Site & Age & Sex & CD56 & $\begin{array}{l}\text { Granzyme } \\
\text { B }\end{array}$ & $\begin{array}{l}\text { TIA- } \\
1\end{array}$ & Perforin & $\mathrm{cCD} 3$ & $\mathrm{CD} 4$ & CD8 \\
\hline 1 & Nasal cavity & 22 & $\mathrm{M}$ & Pos & $\mathrm{Neg}$ & Neg & $\mathrm{Neg}$ & Pos & Neg & $\mathrm{Neg}$ \\
\hline 2 & Nasopharynx & 54 & $\mathrm{M}$ & Pos & $\mathrm{Neg}$ & Neg & $\mathrm{Neg}$ & Pos & Neg & $\mathrm{Neg}$ \\
\hline 3 & $\mathrm{BM}$ & 51 & $\mathrm{M}$ & Pos & $\mathrm{Neg}$ & Pos & $\mathrm{Neg}$ & Pos & Neg & $\mathrm{Neg}$ \\
\hline 4 & Stomach & 74 & $\mathrm{M}$ & Pos & $\mathrm{Neg}$ & Neg & Pos & Pos & Neg & $\mathrm{Neg}$ \\
\hline 5 & Maxilla & 28 & $\mathrm{M}$ & Pos & Pos & Neg & $\mathrm{Neg}$ & Pos & Neg & Neg \\
\hline 6 & Duodenum & 56 & M & Pos & Pos & Neg & $\mathrm{Neg}$ & Neg & Neg & $\mathrm{Neg}$ \\
\hline 7 & Soft palate & 23 & $\mathrm{~F}$ & Pos & Pos & Neg & $\mathrm{Neg}$ & Pos & Neg & Pos \\
\hline 8 & Nasopharynx & 37 & M & Pos & $\mathrm{Neg}$ & Pos & $\mathrm{Neg}$ & Pos & Neg & $\mathrm{Neg}$ \\
\hline 9 & $\begin{array}{l}\text { Nasal } \\
\text { septum }\end{array}$ & 17 & $\mathrm{~F}$ & Pos & $\mathrm{Neg}$ & Pos & $\mathrm{Neg}$ & Pos & Neg & $\mathrm{Neg}$ \\
\hline 10 & Nasal cavity & 50 & $\mathrm{~F}$ & Pos & Pos & Neg & $\mathrm{Neg}$ & Pos & Neg & $\mathrm{Neg}$ \\
\hline 11 & Soft palate & 35 & $\mathrm{~F}$ & Pos & Pos & Neg & $\mathrm{Neg}$ & Pos & Neg & $\mathrm{Neg}$ \\
\hline 12 & $\begin{array}{l}\text { Nasal } \\
\text { septum }\end{array}$ & 8 & M & Pos & Pos & Neg & $\mathrm{Neg}$ & Pos & Neg & Neg \\
\hline 13 & Palate & 61 & $\mathrm{~F}$ & Pos & Neg & Pos & Neg & Pos & Neg & Pos \\
\hline 14 & Skin/breast & 40 & $\mathrm{~F}$ & Pos & Pos & Pos & $\mathrm{Neg}$ & Pos & Neg & $\mathrm{Neg}$ \\
\hline 15 & Stomach & 24 & $\mathrm{M}$ & Pos & Pos & Pos & $\mathrm{Neg}$ & $\mathrm{Neg}$ & Neg & $\mathrm{Neg}$ \\
\hline 16 & Nasal fossa & 51 & M & Pos & Pos & Pos & $\mathrm{Neg}$ & Pos & Neg & $\mathrm{Neg}$ \\
\hline 17 & $\begin{array}{l}\text { Nasal } \\
\text { septum }\end{array}$ & 38 & $\mathrm{~F}$ & Pos & Pos & Pos & $\mathrm{Neg}$ & Pos & Neg & $\mathrm{Neg}$ \\
\hline 18 & Nasopharynx & 42 & $\mathrm{~F}$ & Pos & Pos & Pos & Neg & Pos & Neg & $\mathrm{Neg}$ \\
\hline 19 & Skin & 48 & M & Pos & Pos & Pos & $\mathrm{Neg}$ & Pos & Neg & $\mathrm{Neg}$ \\
\hline 20 & Maxilla & 60 & $\mathrm{M}$ & Pos & Pos & Pos & $\mathrm{Neg}$ & Pos & Neg & $\mathrm{Neg}$ \\
\hline 21 & Caecum & 26 & $\mathrm{~F}$ & Pos & Pos & Neg & Pos & Pos & Neg & $\mathrm{Neg}$ \\
\hline 22 & Testicle & 18 & M & Pos & Pos & Pos & Neg & Pos & Neg & $\mathrm{Neg}$ \\
\hline 23 & Testis & 51 & $\mathrm{M}$ & Pos & $\mathrm{Neg}$ & Neg & $\mathrm{Neg}$ & Pos & Neg & $\mathrm{Neg}$ \\
\hline 24 & Skin & 24 & $\mathrm{M}$ & Pos & Pos & $\mathrm{Neg}$ & Pos & $\mathrm{Neg}$ & Neg & $\mathrm{Neg}$ \\
\hline 25 & Nasal fossa & 44 & $\mathrm{~F}$ & Pos & Pos & Pos & $\mathrm{Neg}$ & Pos & Neg & $\mathrm{Neg}$ \\
\hline 26 & Large bowel & 80 & $\mathrm{M}$ & Pos & $\mathrm{Neg}$ & Pos & Neg & Pos & Neg & $\mathrm{Neg}$ \\
\hline
\end{tabular}

All cases were granulysin and EBER positive. TCR rearrangement is not available in all cases but not two ( $n 3$ and 24$)$ that are polyclonal Pos positive, Neg negative, $M$ male, $F$ female, $B M$ bone marrow, $c C D 3$ cytoplasmic CD3

and 2 out of $50(4 \%)$ peripheral T cell lymphomas, NOS (PTCL, NOS), both showing gamma/delta genotype.

All cases of non-Hodgkin B cell lymphoma, Hodgkin lymphoma and plasma cell myeloma were granulysin negative.

\section{Discussion}

Expression of granulysin in normal and neoplastic lymphoid tissues has been only rarely characterised [8]. In the current study, we show that granulysin is expressed in cytotoxic/NK lymphocytes and in subsets of $\mathrm{NK} / \mathrm{T}$ cell derived lymphomas.

In normal tissues, granulysin marked small numbers of $\mathrm{T} /$ NK-cells within the interfollicular areas of tonsils, lymph nodes and in the red pulp of the spleen. These findings correlate with a previous report describing the expression of granulysin in cytotoxic NK/T cells [4].

Our findings showed that the majority of granulysinpositive cells co-expressed CD56 while most of the CD4+ and CD8+ T cells were negative for granulysin. This suggests that the expression of granulysin is mainly restricted to NK cells and derived neoplasms. Accordingly, we found that the highest level (score 3) of granulysin expression was in a subset of ENKTLs $(71 \%)$ and higher when compared to that of other cytotoxic markers $(p<0.01)$. This finding supported the results of a previous investigation that reported elevated serum levels of granulysin in patients with NK/T cell lymphoma [8]. In the present study, we are not able to quantify serum levels of granulysin from blood samples and to correlate with its expression in tumour tissue. The importance of this analysis was pointed out in a 
Fig. 4 Granulysin is strongly expressed in tumour cells of ENKTL cases that lack other cytotoxic markers. a Granulysin, b granzyme B, c TIA-1, d perforin. In the first case, tumour cells are negative for granzyme $\mathrm{B}$ and perforin but they express weakly TIA-1. [O.M. a-d × 40]
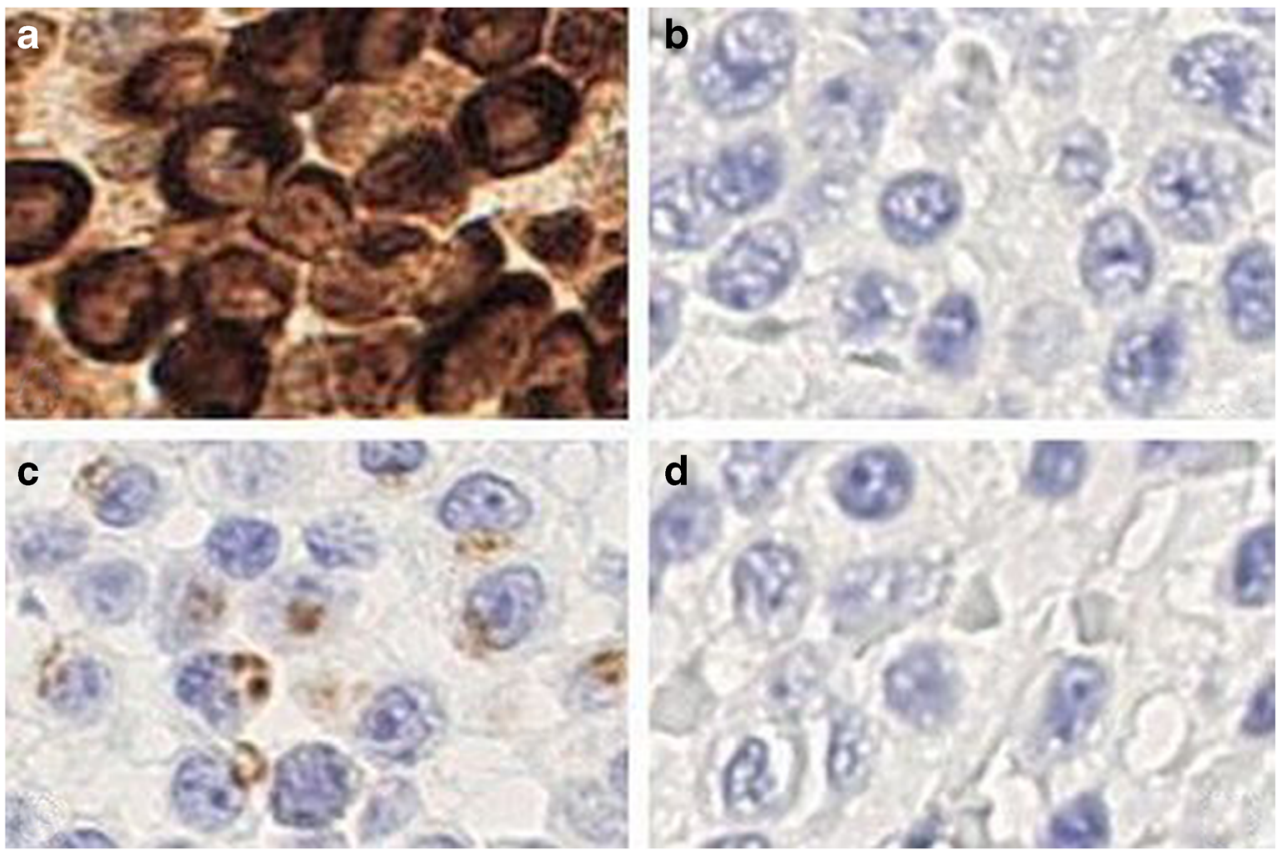

previous investigation being an indicator of disease burden. A significant higher serum level found in ANKL than in ENKTL correlated with increased cancer cells load in the NK cell leukaemia [8]. In fact, serum levels of granulysin significantly decreased after treatment, suggesting its potential role as prognostic marker [8].

The staining pattern of granulysin was comparable to that of commonly used cytotoxic markers granzyme B, TIA-1 and perforin, thus suggesting its diagnostic usefulness in the clinical setting of ENKTLs. This was further highlighted by strong granulysin positivity observed in a proportion of
ENKTLs (30\%) that lacked expression of one or more of the classical cytotoxic markers.

Our results showing granulysin expression in a small proportion of other lymphomas with cytotoxic phenotypes, i.e. ALK-negative ALCL, EATL and PTCL NOS support previous observations of granulysin positivity in systemic ALCL of childhood, in mycosis fungoides (MF) and Sézary syndrome [21, 22]. However, both studies did not give details regarding the number of investigated cases and incidence of granulysin positivity or staining pattern characteristics. In our analysis, we found that in adult
Fig. 5 Granulysin is strongly expressed in tumour cells of ENKTL cases that lack other cytotoxic markers. a Granulysin, b granzyme B, c TIA-1, d perforin. In the second case, tumour cells are negative for TIA1 and perforin but they express weakly granzyme B [O.M. a-d $\times$ 40]
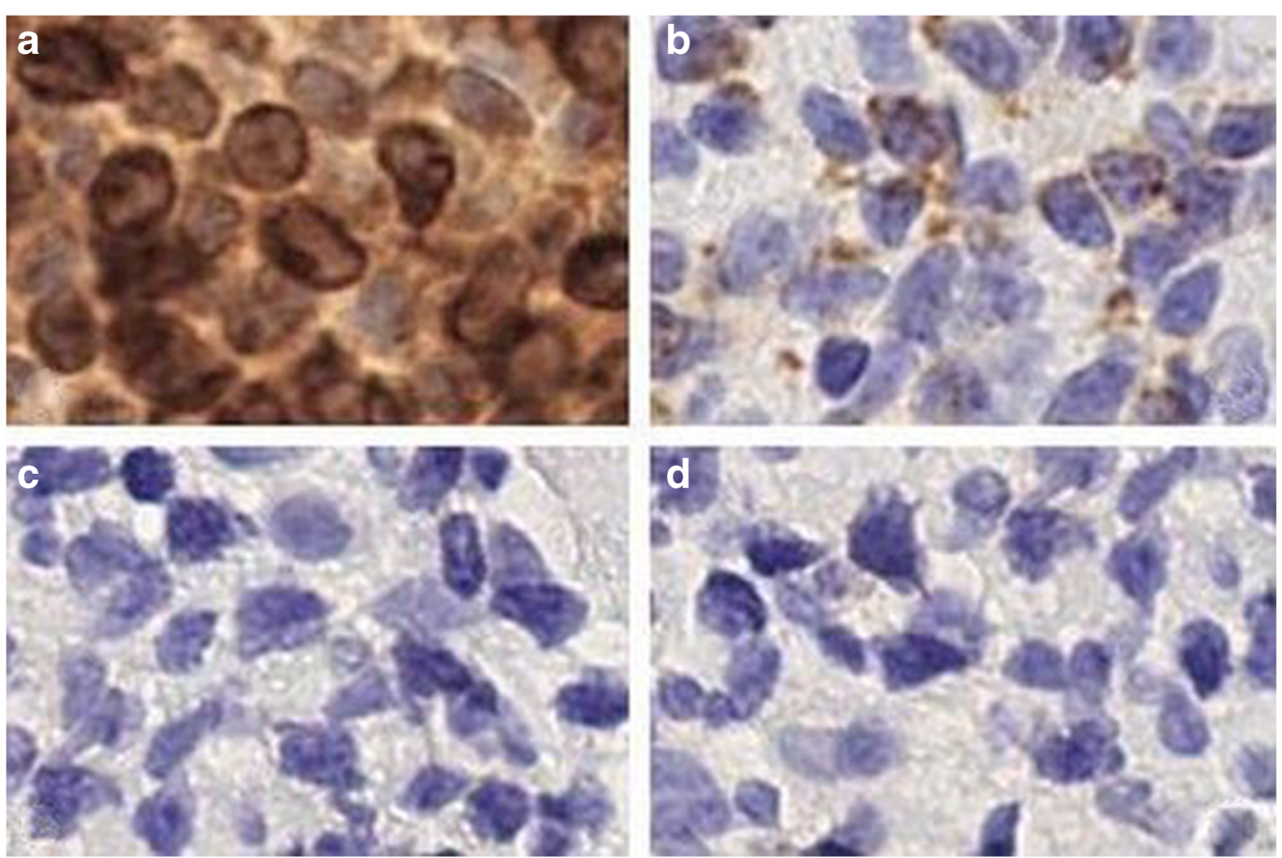
Table 4 Immunohistochemical features of granulysin-negative ENKTL cases

\begin{tabular}{|c|c|c|c|c|c|c|c|c|c|c|}
\hline Case & Site & Age & Sex & CD56 & Granzyme B & $\begin{array}{l}\text { TIA- } \\
1\end{array}$ & Perforin & $\mathrm{cCD} 3$ & CD4 & CD8 \\
\hline 1 & Nasal cavity & 41 & M & Pos & Pos & Pos & $\mathrm{Neg}$ & Pos & $\mathrm{Neg}$ & $\mathrm{Neg}$ \\
\hline 2 & Palate & 65 & $\mathrm{~F}$ & Pos & $\mathrm{Neg}$ & Pos & $\mathrm{Neg}$ & Pos & $\mathrm{Neg}$ & $\mathrm{Neg}$ \\
\hline 3 & Palate & 47 & M & Pos & Pos & Neg & $\mathrm{Neg}$ & Pos & $\mathrm{Neg}$ & Pos (weak) \\
\hline 4 & Nasal fossa & 53 & M & Pos & Pos & Pos & $\mathrm{Neg}$ & Pos & $\mathrm{Neg}$ & $\mathrm{Neg}$ \\
\hline 5 & Nasal fossa & 58 & $\mathrm{~F}$ & Pos & $\mathrm{Neg}$ & Pos & $\mathrm{Neg}$ & Pos & $\mathrm{Neg}$ & $\mathrm{Neg}$ \\
\hline 6 & Nasal fossa & 54 & M & Pos & Pos & Neg & $\mathrm{Neg}$ & Pos & $\mathrm{Neg}$ & $\mathrm{Neg}$ \\
\hline 7 & Nasal sinus & 45 & M & Pos & Pos & Pos & $\mathrm{Neg}$ & Pos & Neg & $\mathrm{Neg}$ \\
\hline 8 & Nasal sinus & 44 & $\mathrm{~F}$ & Pos & Pos & Pos & $\mathrm{Neg}$ & Pos & $\mathrm{Neg}$ & $\mathrm{Neg}$ \\
\hline 9 & Lymph node & 51 & $\mathrm{~F}$ & Pos & Pos & Pos & Pos & Pos & $\mathrm{Neg}$ & Neg \\
\hline 10 & $\mathrm{BM}$ & 52 & M & Pos & Pos & Pos & Pos & Pos & $\mathrm{Neg}$ & $\mathrm{Neg}$ \\
\hline 11 & Palate & 35 & M & Pos & $\mathrm{Neg}$ & Pos & $\mathrm{Neg}$ & Pos & $\mathrm{Neg}$ & $\mathrm{Neg}$ \\
\hline 12 & Nasal cavity & 42 & M & Pos & Pos & Pos & $\mathrm{Neg}$ & Pos & $\mathrm{Neg}$ & $\mathrm{Neg}$ \\
\hline 13 & Nasal cavity & 61 & $\mathrm{~F}$ & Pos & $\mathrm{Neg}$ & Pos & Pos & $\mathrm{Neg}$ & $\mathrm{Neg}$ & $\mathrm{Neg}$ \\
\hline 14 & Nasal cavity & 54 & M & Pos & Pos & Pos & $\mathrm{Neg}$ & Pos & $\mathrm{Neg}$ & $\mathrm{Neg}$ \\
\hline 15 & Oral cavity & 63 & $\mathrm{~F}$ & Pos & Pos & Pos & Pos & Pos & $\mathrm{Neg}$ & $\mathrm{Neg}$ \\
\hline 16 & Palate & 47 & M & Pos & Pos & Pos & $\mathrm{Neg}$ & Pos & Neg & Neg \\
\hline 17 & Palate & 52 & M & Pos & Pos & Neg & Neg & Pos & Neg & $\mathrm{Neg}$ \\
\hline 18 & Nasal cavity & 48 & $\mathrm{~F}$ & Pos & Pos & Neg & Neg & Pos & $\mathrm{Neg}$ & $\mathrm{Neg}$ \\
\hline 19 & Maxilla & 41 & M & Pos & Pos & Pos & $\mathrm{Neg}$ & Pos & $\mathrm{Neg}$ & $\mathrm{Neg}$ \\
\hline 20 & Lymph node & 60 & M & Pos & Pos & Pos & $\mathrm{Neg}$ & Pos & $\mathrm{Neg}$ & $\mathrm{Neg}$ \\
\hline 21 & Nasal cavity & 53 & M & Pos & Pos & Pos & Pos & Pos & $\mathrm{Neg}$ & $\mathrm{Neg}$ \\
\hline 22 & Nasal fossa & 49 & $\mathrm{~F}$ & Pos & Pos & NA & NA & Pos & Neg & $\mathrm{Neg}$ \\
\hline 23 & Nasal cavity & 41 & M & Pos & Pos & NA & NA & Pos & Pos (focal) & $\mathrm{Neg}$ \\
\hline 24 & Nasal cavity & 57 & $\mathrm{~F}$ & Pos & Pos & Pos & NA & Pos & $\mathrm{Neg}$ & Pos \\
\hline 25 & Nasal cavity & 54 & M & Pos & Pos & Pos & NA & Pos & Neg & Pos \\
\hline
\end{tabular}

All cases were EBER positive and granulysin negative. TCR rearrangement is not available in all cases but not one $(n 11)$ that is polyclonal

Pos positive, Neg negative, $N A$ not available, $M$ male, $F$ female, $B M$ bone marrow

ALK-negative ALCLs, the expression of granulysin was less strong and intense than in ENKTL cases and in addition restricted to a small proportion of tumour cells (less than 25\%; score 1).

Although we found granulysin expression in the majority of ENKTCL cases, further experiments with NK and cytotoxic $\mathrm{T}$ cell lines are required to demonstrate granulysin as a cytotoxic marker of NK cells and derived lymphomas and to correlate with cell of origin (NK versus $\mathrm{T}$ cell).

Finally, it should be mentioned that granulysin may represent a potential therapeutic target for NK/T cell lymphomas that are characterised by a poor prognosis [5]. Notoriously, successful disease control is rarely achieved in most ENKTL patients with relapsed or refractory diseases, and consistent with several international clinicopathological studies [23], the treatment of ENKTL nasal type differs according to the stage of the disease. Patients with systemic disease tend to be treated with L-asparaginase-containing regimens and although showed best results, toxicity is not negligeable [23]. Thus, development of tailored drugs targeted to novel biomarkers, and granulysin might represent one, should be considered in order to improve treatment outcome.

In conclusion, our study suggests granulysin as an additional molecule for cytotoxic and NK/T cells as well as a reliable diagnostic marker for $\mathrm{NK} / \mathrm{T}$ cell-derived lymphoma subtypes and useful for those ENKTLs that lack expression of one or more of the commonly used cytotoxic markers.

Our results open new insights for future investigations aimed to validate the clinical value of granulysin to monitor disease in biopsies post-therapy.

Author's contributions TM, LL and SAP conceived and designed the study; GLB, MRA, MP, SD, SAP, LL and TM wrote, edited and reviewed the manuscript. GLB, AUA, YN, AC, ES, MDL, HMK, SZ, AR and MRG researched and analysed data. All authors gave final approval for publication. TM takes full responsibility for the work as a whole, including the study design, access to data and the decision to submit and publish the manuscript. 


\section{Compliance with ethical standards}

The present study was conducted according to the principles of the Helsinki declaration after approval of the internal review board, the National Research Ethics Service, Research Ethics Committee 4 (REC Reference number 09/H0715/64).

Conflict of interest The authors declare that they have no conflict of interest.

Open Access This article is distributed under the terms of the Creative Commons Attribution 4.0 International License (http:// creativecommons.org/licenses/by/4.0/), which permits unrestricted use, distribution, and reproduction in any medium, provided you give appropriate credit to the original author(s) and the source, provide a link to the Creative Commons license, and indicate if changes were made.

\section{References}

1. Stenger S, Hanson DA, Teitelbaum R, Dewan P, Niazi KR, Froelich CJ, Ganz T, Thoma-Uszynski S, Melián A, Bogdan C, Porcelli SA, Bloom BR, Krensky AM, Modlin RL (1998) An antimicrobial activity of cytolytic $\mathrm{T}$ cells mediated by granulysin. Science 282(5386):121-125. https://doi.org/10.1126/science.282.5386.121

2. Obata-Onai A, Hashimoto S, Onai N, Kurachi M, Nagai S, Shizuno KI, Nagahata T, Matsushima K (2002) Comprehensive gene expression analysis of human NK cells and CD8(+) T lymphocytes. Int Immunol 14(10):1085-1098

3. Pont F, Familiades J, Déjean S, Fruchon S, Cendron D, Poupot M, Poupot R, L'Faqihi-Olive F, Prade N, Ycart B, Fournié JJ (2012) The gene expression profile of phosphoantigen-specific human $\gamma \delta$ $\mathrm{T}$ lymphocytes is a blend of $\alpha \beta$ T-cell and NK-cell signatures. Eur J Immunol 42(1):228-240. https://doi.org/10.1002/eji.201141870

4. Pena SV, Hanson DA, Carr BA, Goralski TJ, Krensky AM (1997) Processing, subcellular localization, and function of 519 (granulysin), a human late $\mathrm{T}$ cell activation molecule with homology to small, lytic, granule proteins. J Immunol 158(6):2680-2688

5. Krensky AM, Clayberger C (2009) Biology and clinical relevance of granulysin. Tissue Antigens 73(3):193-198. https://doi.org/10. 1111/j.1399-0039.2008.01218.x

6. Okada S, Morishita T (2012) The role of granulysin in cancer immunology. ISRN Immunol 2012:1-5. https://doi.org/10.5402/ 2012/876203

7. Kishi A, Takamori Y, Ogawa K, Takano S, Tomita S, Tanigawa M, Niman M, Kishida T, Fujita S (2002) Differential expression of granulysin and perforin by NK cells in cancer patients and correlation of impaired granulysin expression with progression of cancer. Cancer Immunol Immunother 50(11):604-614. https://doi.org/10. $1007 / \mathrm{s} 002620100228$

8. Sekiguchi N, Asano N, Ito T, Momose K, Momose M, Ishida F (2012) Elevated serum granulysin and its clinical relevance in mature NK-cell neoplasms. Int J Hematol 96(4):461-468. https://doi. org/10.1007/s12185-012-1159-x

9. Chan JKC, Quintanilla-Martinez L, Ferry JA (2017) Extranodal NK/T-cell lymphoma, nasal type. In: Swerdlow SH, Campo E, Harris et al (eds) WHO classification of tumours of haematopoietic and lymphoid, 4th edition. International Agency for research on Cancer (IARC), Lyon, pp 368-371

10. Gualco G, Domeny-Duarte P, Chioato BG, Natkunam Y, Bacchi CE (2011) Clinicopathologic and molecular features of 122 Brazilian cases of nodal and extranodal NK/T-cell lymphoma, nasal type, with EBV subtyping analysis. Am J Surg Pathol 35(8):11951203. https://doi.org/10.1097/PAS.0b013e31821ec4b5

11. Takata K, Hong ME, Sitthinamsuwan P, Loong F, Tan SY, Liau JY, Hsieh PP, Ng SB, Yang SF, Pongpruttipan T, Sukpanichnant S, Kwong YL, Hyeh Ko Y, Cho YT, Chng WJ, Matsushita T, Yoshino T, Chuang SS (2015) Primary cutaneous NK/T-cell lymphoma, nasal type and CD56-positive peripheral T-cell lymphoma: a cellular lineage and clinicopathological study of 60 patients from Asia. Am J Surg Pathol 39(1):1-12. https://doi.org/10.1097/PAS. 0000000000000312

12. Kim SJ, Jung HA, Chuang SS et al (2013) Extranodal natural killer/ T-cell lymphoma involving the gastrointestinal tract: analysis of clinical features and outcomes from the Asia Lymphoma Study Group. J Hematol Oncol 6:86. https://doi.org/10.1186/1756-87226-86

13. Kim TH, Kim JS, Suh YG, Cho J, Yang WI, Suh CO (2016) The roles of radiotherapy and chemotherapy in the era of multimodal treatment for early-stage nasal-type extranodal natural killer/T-cell lymphoma. Yonsei Med J 57(4):846-854. https://doi.org/10.3349/ ymj.2016.57.4.846

14. Cheuk W, Chan KCJ (2010) NK-cell neoplasms. In: Jaffe ES et al (eds) Hematopathology $1^{\text {st }}$ edition. Saunders, Philadelphia, pp 473 486

15. Ko YH, Jaffe ES (2010) Epstein-Barr virus-positive systemic Tlymphoproliferative disorders and related lymphoproliferations of childhood. In: Jaffe ES et al (eds) Hematopathology 1st edition. Saunders, Philadelphia, pp 493-498

16. Hsu FD, Nielsen TO et al (2002) Tissue microarrays are an effective quality assurance tool for diagnostic immunohistochemistry. Mod Pathol 15(12):1374-1380. https://doi.org/10.1097/01.MP. ooooo39571.02827.CE

17. Marafioti T, Paterson JC, Ballabio E, Reichard KK, Tedoldi S, Hollowood K, Dictor M, Hansmann ML, Pileri SA, Dyer MJ, Sozzani S, Dikic I, Shaw AS, Petrella T, Stein H, Isaacson PG, Facchetti F, Mason DY (2008) Novel markers of normal and neoplastic human plasmacytoid dendritic cells. Blood 111:3778-3792. https://doi.org/10.1182/blood-2007-10-117531

18. Marafioti T, Jones M, Facchetti F et al (2003) Phenotype and genotype of interfollicular large B cells, a subpopulation of lymphocytes often with dendritic morphology. Blood 102(8):2868-2876. https://doi.org/10.1182/blood-2003-03-0692

19. Rocca BJ, Ginori A, Barone A, Calandra C, Crivelli F, de Falco G, Gazaneo S, Tripodi S, Cevenini G, del Vecchio MT, Ambrosio MR, Tosi P (2015) Translationally controlled tumor protein in prostatic adenocarcinoma: correlation with tumor grading and treatmentrelated changes. Biomed Res Int 2015:985950-985958. https:// doi.org/10.1155/2015/985950

20. Ambrosio MR, Rocca BJ, Barone A, Mastrogiulio MG, Costa A, Bellan C, Lazzi S (2014) Primary anorectal Hodgkin lymphoma: report of a case and review of the literature. Hum Pathol 45(3):648 652. https://doi.org/10.1016/j.humpath.2013.09.015

21. Kitamura N, Katagiri, Itagaki M et al (2009) The expression of granulysin in systemic anaplastic large cell lymphoma in childhood. Leuk Res 33(7):908-912. https://doi.org/10.1016/j.leukres.2009. 01.032

22. Shareef MM, Elgarhy LH, Wasfy R-S (2015) Expression of granulysin and FOXP3 in cutaneous T cell lymphoma and Sézary syndrome. Asian Pac J Cancer Prev 16(13):5359-5364. https://doi. org/10.7314/APJCP.2015.16.13.5359

23. Corradini P, Marchetti M, Barosi G, Billio A, Gallamini A, Pileri S, Pimpinelli N, Rossi G, Zinzani PL, Tura S (2014) SIE-SIESGITMO guidelines for the management of adult peripheral T- and NK-cell lymphomas, excluding mature T-cell leukaemias. Ann Oncol 25(12):2339-2350. https://doi.org/10.1093/annonc/mdu152 